\title{
Field Testing of a Proposed Pavement Marking as a Red Light Running Countermeasure
}

\author{
Noor Elmitiny ${ }^{*}, 1$, Essam Radwan ${ }^{1}$, Xuedong Yan $^{2}$ and Mutasem Jardaneh ${ }^{1}$ \\ ${ }^{1}$ Department of Civil \& Environmental Engineering, University of Central Florida, USA \\ ${ }^{2}$ Center for Transportation Research, University of Tennessee, 309 Conference Center Bldg., Knoxville, TN 37996-4133, \\ USA
}

\begin{abstract}
When a motorist approaches a signalized intersection during the signal change period (changing from green to yellow), he/she is required to make a stop/go decision. A proposed pavement marking with a word message of "SIGNAL AHEAD" was proposed to be positioned at the stop sight distance from the intersection stop-bar to assist the driver in making a proper stop/go decision without running a red light or making an abrupt stop. This paper examined effectiveness of the marking as a red light running violation countermeasure through a field study. Red light running behaviors were recorded at a test intersection (with marking) and a control intersection (without marking) as a comparison. A reduction in the red light running rate was observed after the marking was applied at the test intersection, while the red light running rate did not shift significantly at the control intersection, leading to the conclusion that the marking has a good potential as a red light running countermeasure.
\end{abstract}

Keywords: Red light running, pavement marking, dilemma zone, before-after study and signal change.

\section{INTRODUCTION}

When a driver encounters a signal change from green to yellow, he/she is required to make a stop/go decision based on speed and distance to the stop bar. Making a wrong decision may lead to red light running (RLR) violation or slamming on brakes harshly. It increases the probabilities of rear-end or angle crashes. On a national basis, RLR and rearend crashes result in substantial numbers of severe injuries and property damages. It was estimated that RLR resulted in 260,000 crashes each year, of which approximately 750 were fatal [1]. Porter and England observed 5,112 drivers entering six traffic-controlled intersections in three cities and found that $35.2 \%$ of observed light cycles had at least one red light runner prior to the onset of opposing traffic [2]. Although rear-end crashes account for $29.6 \%$ of all reported crashes in the United States, [3] they constitute more than $40 \%$ percent of all reported intersection crashes. A prior study indicated that most of rear-end crashes at a signalized intersection occur when two successive drivers approaching the intersection make conflicting decisions when the yellow signal appears [4]. Therefore, there is a need for a tool to help the motorists make better stop/go decisions to reduce RLR and eliminate the conflict in the decision between drivers.

The yellow signal change is used to warn approaching drivers of an imminent change in right of way at intersections. At the onset of the yellow signal indication, drivers who are close to intersections may clear the intersections before the signal indication changes to red,

*Address correspondence to this author at the Department of Civil \& Environmental Engineering, University of Central Florida, USA; Tel: (407) 823-1056; Fax: (407) 823-4676; E-mail: nelmitiny@yahoo.com while drivers who are far enough from the intersections should stop at the intersections. Drivers' incorrect decisions of crossing the intersections at the onset of the yellow change may lead to RLR violations or traffic conflicts with the vehicles in front of them, whose drivers decide to stop at the intersections. A previous study [5] categorized three groups of red-light violators: [1] drivers who could have cleared the intersection before the red, but were delayed either by their own indecision or by slower traffic in front of them; [2] drivers in the dilemma zone; and [3] those aggressive drivers who could have stopped comfortably, but chose to run the red light deliberately.

The dilemma zone as defined by the Federal Highway Administration is the area upstream the stop bar at signalized intersections in which the drivers are indecisive about the stop or go decision [6]. Many studies reported that both dilemma and option zones existing upstream of intersections at the onset of yellow signal, are associated with the larger variability in the drivers' stop/go decisions $[4,7,8]$. When driver is going at speed lower than the speed limit, an option zone is created. When the driver is traveling higher than the speed limit, a dilemma zone is created [9]. When vehicles are located in an option zone, drivers can either easily stop before the stop line or successfully clear the intersection before the onset of the red signal. The option zones existence may contribute to rear-end conflicts due to the diversity of the drivers' stop/go decisions. On the contrary, drivers who are in a dilemma zone can neither stop, nor cross the stop line before the signal turns red. The dilemma zone is also described as a zone based on a probabilistic function by Zegeer [10], who defined the dilemma zone as the zone upstream the stop bar where more than $10 \%$ and less than $90 \%$ of the drivers make the stop decision. Therefore, the dilemma and option zones existence may result in both rearend conflicts and RLR violations. 
In 2007, Yan et al. [11] proposed the application of a pavement marking with a word message 'SIGNAL AHEAD' (see Fig. 1) positioned in order to help drivers in the decision to stop or go at the onset of the yellow at a signalized intersection. The effectiveness of the marking as RLR countermeasure was tested using driving simulator. The experiment results indicated that the marking information led to reducing the region of driver uncertainty and contributed to a lower red light running rate.

The 'SIGNAL AHEAD' pavement marking is already listed in the Manual on Uniform Traffic Control Devices [12] as a warning word marking to alert drivers of a signalized intersection existence. However, there are no field studies reporting on where the marking should be positioned at intersections and what is the effectiveness of this countermeasure. Due to the positive effect of the marking found in the driving simulator experiment, a before-after field study for the marking countermeasure was conducted to testify and validate the simulator study results. This paper presents design and details of marking application, the relevant before-after observation method, and the effectiveness of marking on RLR rate.

\section{MARKING DESIGN}

The marking consists of the sentence 'SIGNAL AHEAD' written on the pavement between two 1 foot wide horizontal lines. The marking is white painting and the sentence "SIGNAL AHEAD" is repeated in each lane. The marking details according to the Manual of Uniform Traffic Control Devices (MUTCD) standards are shown in Fig. (1a). For installing the marking in three lanes, the detailed dimension of the marking letters is shown in Fig. (1b).

In this study, it is suggested to position the markings at a distance equivalent to the stop sight distance, thus permitting vehicles to stop safely if they have not reached the pavement marking at the onset of the yellow. So, the stop sight distance is calculated based on design speed and deceleration rate, which is referenced in the ITE's Traffic Engineering Handbook (7), as shown in Equation 1:

$$
X=V t+\frac{V^{2}}{2 a+64.4 g}
$$

where:

$\mathrm{X}=$ distance from the marking to the stop bar $(\mathrm{ft})$

$\mathrm{V}=$ design speed $(\mathrm{ft} / \mathrm{s})$

$\mathrm{t}=$ reaction time $(1.0 \mathrm{~s})$

$\mathrm{a}=$ average deceleration rate $\left(10 \mathrm{ft} / \mathrm{s}^{2}\right)$

$\mathrm{g}=$ grade of the intersection approach $(\mathrm{g}=0$, level road).

The intent of the marking design is that when drivers are located upstream of the marking at the onset of the yellow signal they are encouraged to stop at the intersection; on the other hand, when drivers are located downstream of the marking, they are safe to cross the intersection. Potentially, the marking provides the driver with relative position reference: whether he/she can cross the intersection safely or not at the onset of the yellow signal.
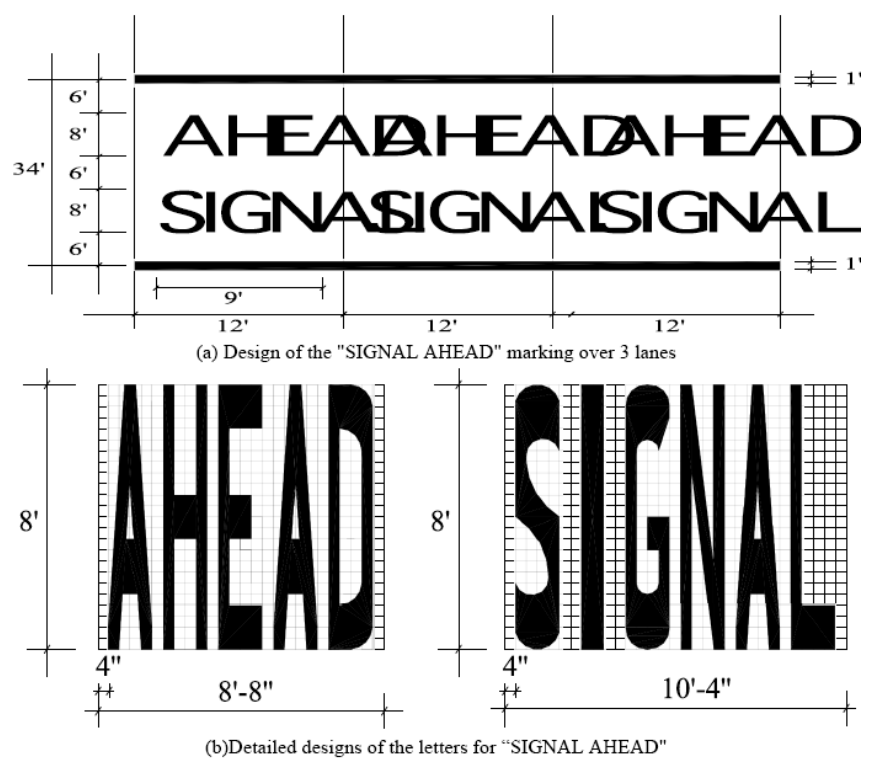

Fig. (1). Design and details of the marking.

\section{STUDY METHOD}

\section{Intersection Selection}

Two intersections were chosen to conduct the field experiment: "Alafaya Trl. and Gemini Blvd." and "Alafaya Trl. and Central Blvd." (See Fig. 2a, b) They are located along the same three lane highway in the east Orlando metropolitan area (N. Alafaya Trl.). The two intersections "Alafaya Trl. and Gemini Blvd." and "Alafaya Trl. and Central Blvd." have similar geometric characteristics and the same posted speed limit (45 mph). The "Alafaya Trl. and Gemini Blvd." intersection was used as test intersection for marking installation. The marking was installed upstream of the northbound approach of the test intersection. Using a road design speed of $50 \mathrm{mph}$ (for the $45 \mathrm{mph}$ posted speed limit), the distance from the stop bar to the marking is calculated to be $315 \mathrm{ft}$ measured to the centerline of the pavement marking. The marking positioning details are shown in Fig. (3). The "Alafaya Trl. and Central Blvd." served as a control intersection without marking application, which was used to monitor the general RLR trend changes during the study period.

\section{Data Collection}

The method used to conduct this experiment was monitoring the two intersections (as practical factors can permit) for a period of time to measure the RLR rates. To test the marking effectiveness we divided the study time frame in to three time periods: "before", "after", and "after media". Experiment time line is illustrated in Table 1. The first period "before" was for monitoring RLR rates before the marking installation. After a monitoring period we name it as the "before" period, the marking was installed only at the test intersection. Both of the intersections were monitored for another three months without informing the motorists about the marking. A media campaign followed to educate the motorists about the marking and how it should be used to make better stop/go decisions. After the media 


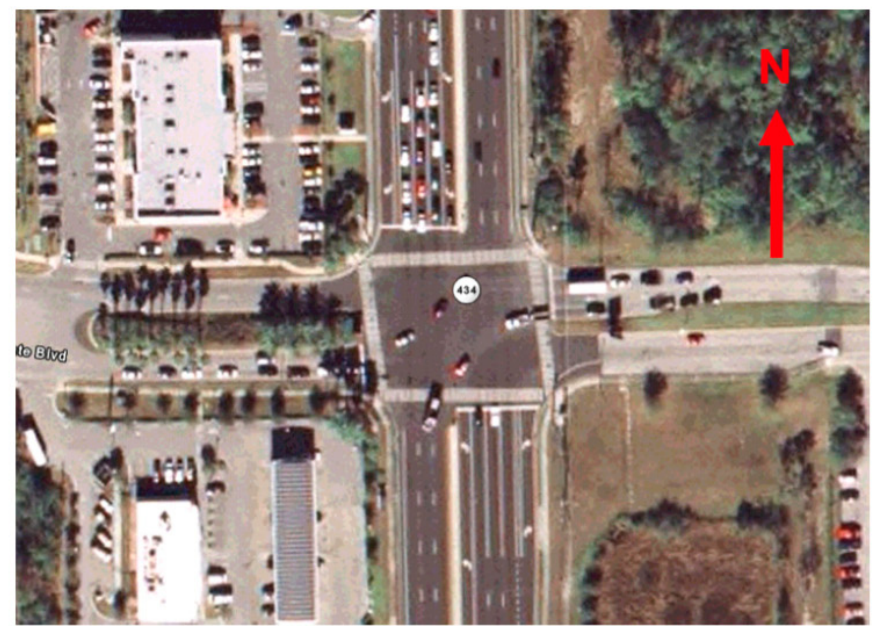

(a). Alafaya Trl. and Gemini Blvd. (test intersection)

Fig. (2). Illustration of the selected intersections.

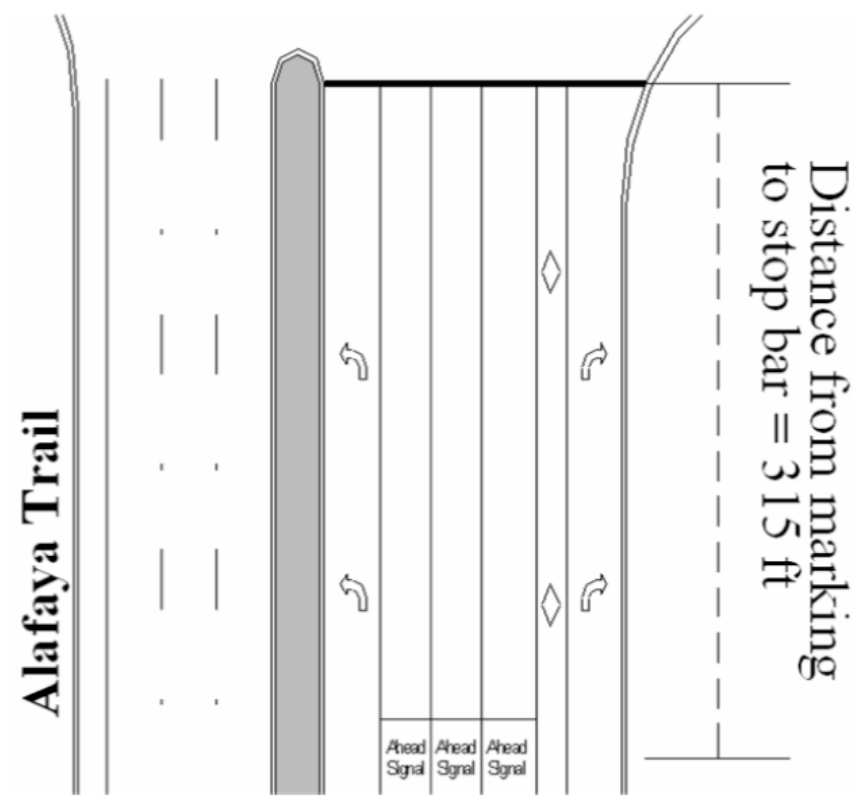

Fig. (3). Marking position from the stop bar.

campaign completion, the intersections were monitored again to determine the marking full effect. This period was called "after media" period. Traffic monitoring camera systems were installed in the two intersections. Iteris traffic monitoring cameras were used; each camera was connected to a processor in the signal controller cabinet, the processor was connected to the signal controller to get the cycle length and signal phase. The system counted the total number of red

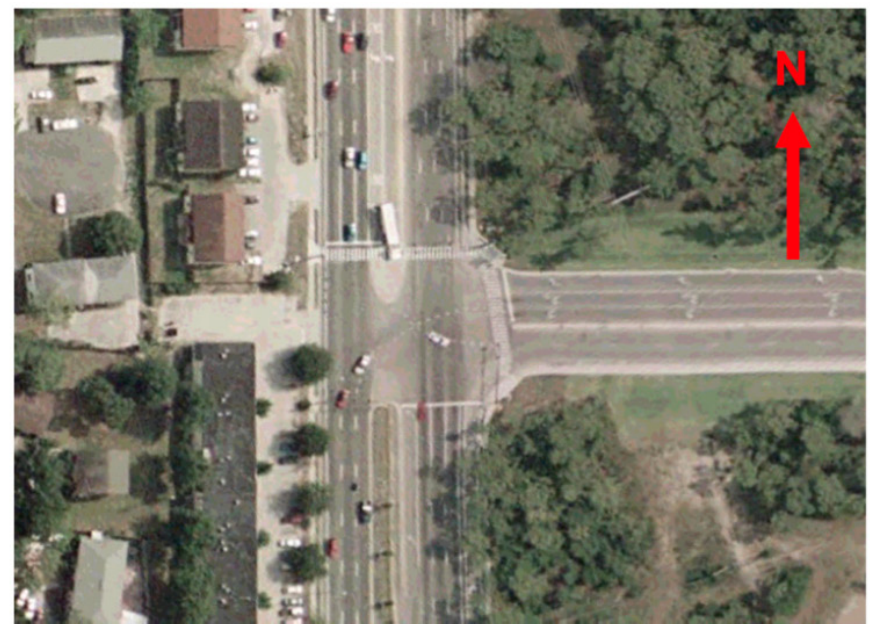

(b). Alafaya Trl. and Central Blvd (control intersection)

light runners and traffic volume for each $15 \mathrm{~min}$. The layouts of the monitoring cameras at test and control intersections are shown in Fig. (4a) test intersection site and Fig. (4b) the control intersection site.

\section{Marking Installation}

The marking was installed at the test intersection location on the September $4^{\text {th }}, 2007$. Because the marking is still in the early testing phase, the local officials did not want a permanent marking to be installed, which may damage the pavement during removal at the end of the experiment. For this reason a temporary marking (paint instead of tape) was used for the study, which will wear off with time. Fig. (5) shows the marking as it appears at the test intersection.

\section{RESULTS}

\section{Preliminary Analysis}

RLR is a rare event in its nature and primarily depends on the number of drivers who encounter signal change and make wrong decisions. Thus, more drivers have a chance to run red light in heavier traffic conditions. The traffic volume was used as a measure of this chance to run red light. The higher the volume, the higher the probability of encountering a yellow signal change thus increasing the probability of RLR. As a measure of effectiveness for this study it was decided to use the RLR rates, calculated as (RLR rate = number of RLR vehicles / the volume of traffic * 1000; units of the RLR rate is RLR/hr/1000veh). This rate uses the volume of traffic to normalize the red light running over the different times of the day.

Table 1. Experiment Periods Time Line

\begin{tabular}{|c|c|c|c|c|c|c|c|c|c|c|c|c|c|}
\hline $\begin{array}{c}\text { Year } \\
\text { Month }\end{array}$ & \multicolumn{7}{|c|}{2007} & \multicolumn{6}{|c|}{2008} \\
\hline "Before" Period & & & & & & & & & & & & & \\
\hline “After" Period & & & & & & & & & & & & & \\
\hline Media Campaign & & & & & & & & & & & & & \\
\hline
\end{tabular}




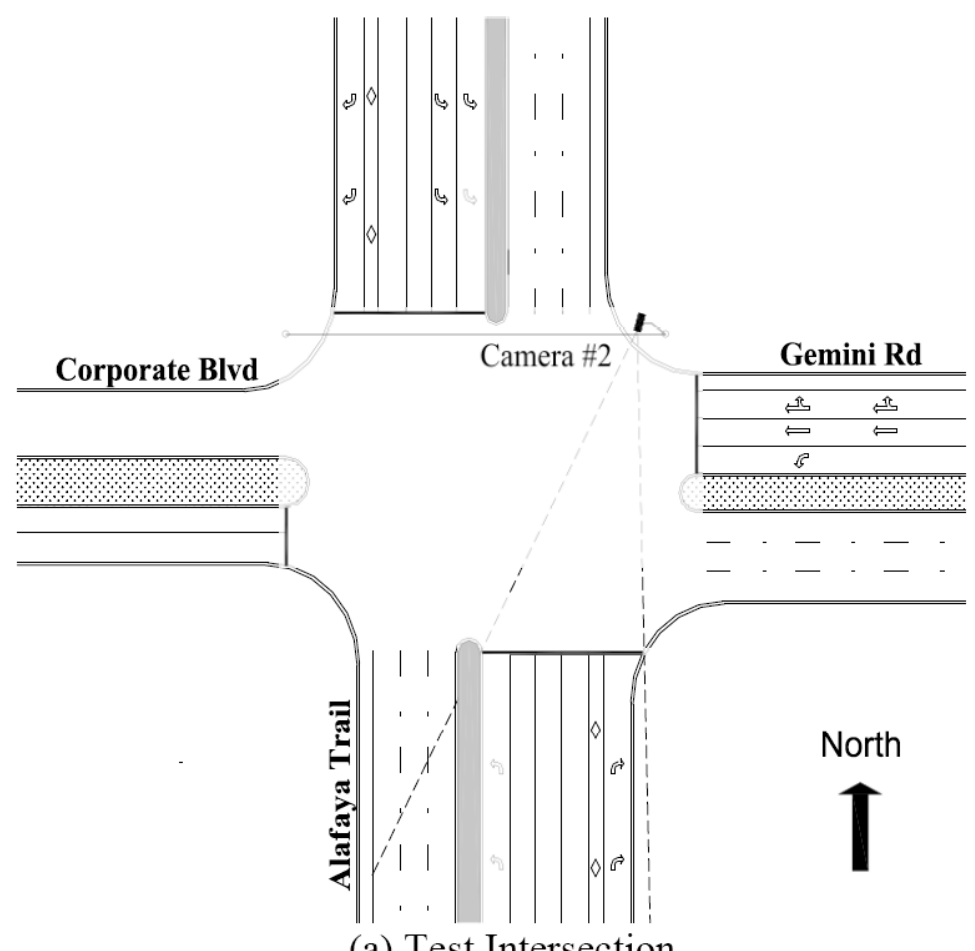

(a) Test Intersection

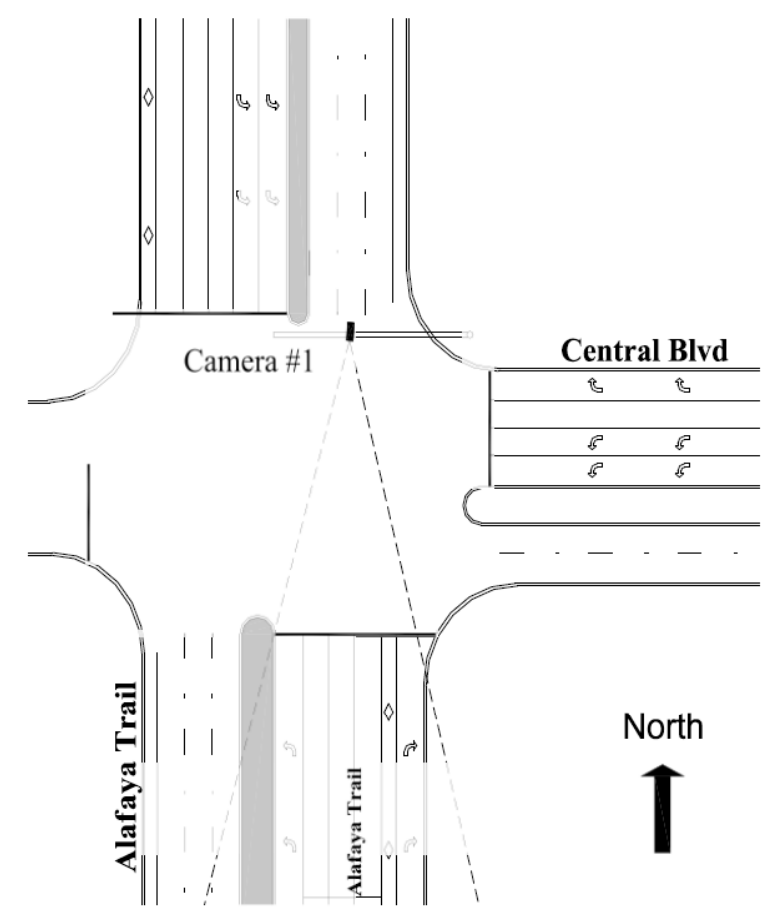

(b) Control intersection

Fig. (4). Illustration of camera position.

Analyzing the "before" period data (June, July and August 2007), each data point contains the number of RLR in certain $15 \mathrm{~min}$ period and the corresponding volume of traffic that passed through the intersection (data is recorded for each lane separately). Each data point was then multiplied by four to get equivalent hourly rates.

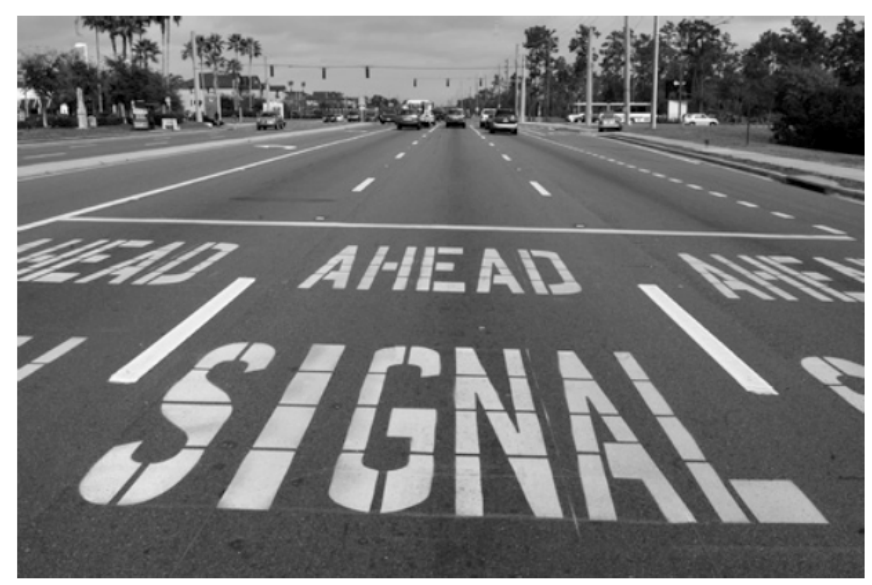

Fig. (5). Marking view from a vehicle.

By plotting the RLR rate (average of each hour for three months) in comparison to the volume we observed that both the test and control intersections had the peak RLR rate during the lowest traffic volume conditions as shown in Fig. (6a, b). Although both intersections exhibited this RLR phenomena behavior, this finding should not be generalized because more intersections need to be analyzed before making any conclusive relations.

Examining the RLR rate at the test and control intersections, it was observed that the test intersection has a higher RLR rate than the control intersection as Fig. (7) shows. To determine the effectiveness of the marking the research group decided to use the RLR rate difference between the two intersections. The average difference between the test and the control intersection for the "before" period is 53 red light runner $/ \mathrm{hr} / 1000 \mathrm{veh}$.

\section{Media Campaign}

Four months after marking installation (the "after" period), a media campaign was conducted to inform the public about the marking; how is the "SIGNAL AHEAD" marking supposed to function to help the motorist make the right stop/go decision on encountering a change period. The public education campaign had to cover as much audience as possible. Because the intersection is located just outside the University of Central Florida main campus, an important part of the media campaign was the on campus media, in addition to public TV stations and news papers.

The wftv.com9 covered the story; their coverage included the purpose of the marking and details about how it should be used. Also on the news channel website they published a complete description of the experiment and its different time periods.

The Central Florida Future is the University of Central Florida on campus official newspaper for the student body and faculty. Through this news paper the new marking was covered extensively. The research topic was first page topic on Wednesday, February 6, 2008. The University of Center Florida News and Information website have the story published online with two photographs illustrating how the marking looks on the pavement. In addition to that, all the UCF students, staff and faculty received an email explaining the marking and what is its purpose. 


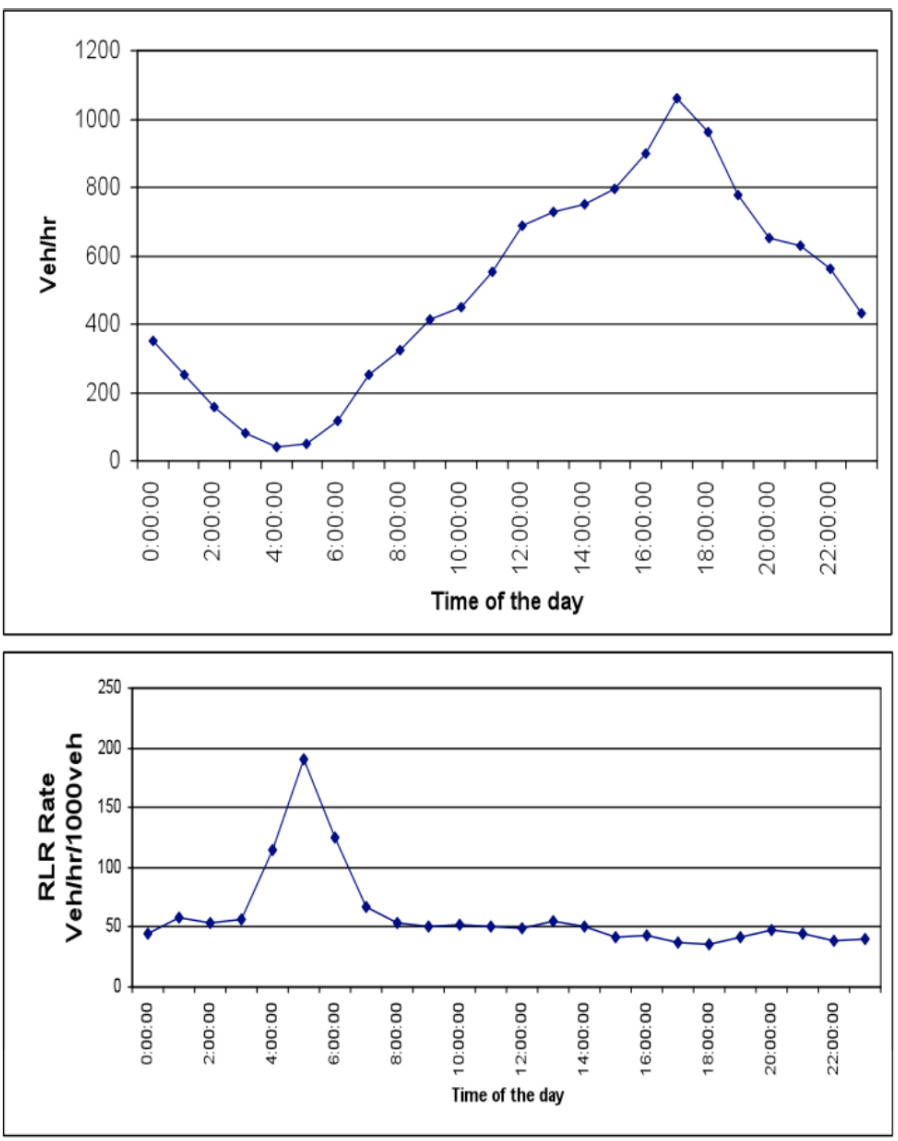

(a) Test Intersection
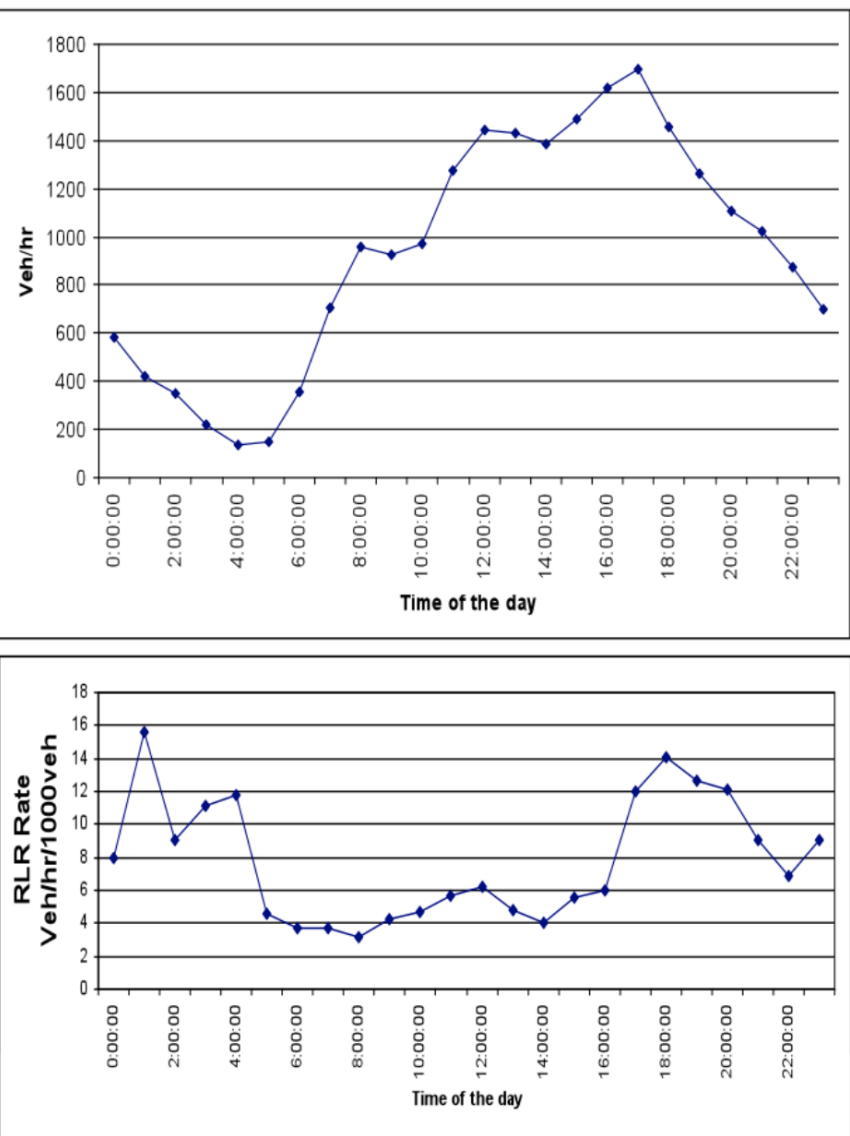

(b) Control Intersection

Fig. (6). Relation between red light runing rate and traffic volume.

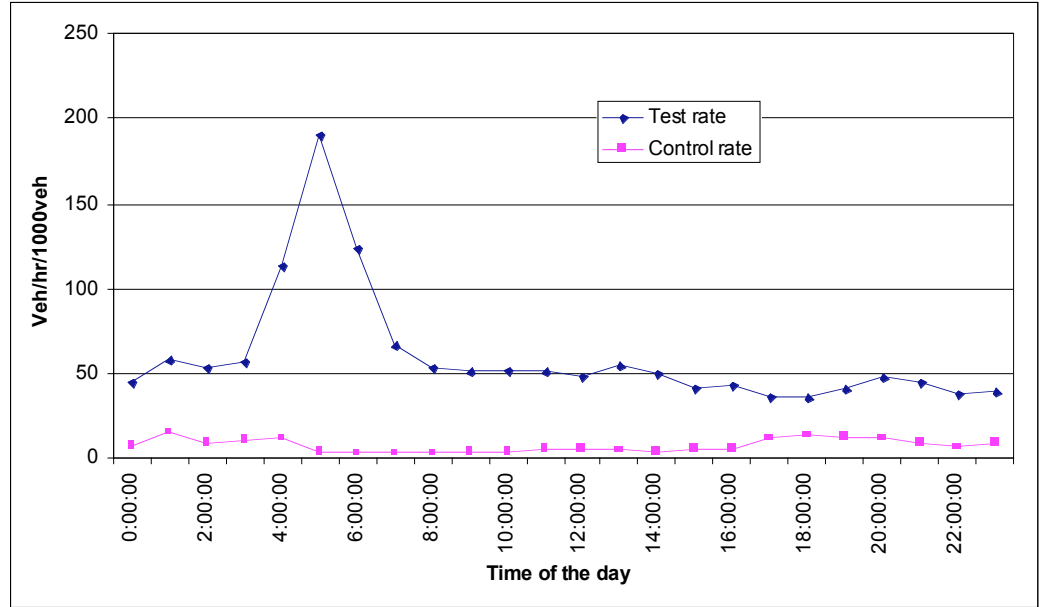

Fig. (7). Average RLR rate of before period (red light runner/hr/1000veh).

To follow the effect of the media campaign, first the research group needs to determine its effectiveness in conveying the massage to the target motorists. A survey was designed to measure the degree of penetration that the media campaign has reached.

The survey had four main questions:

- Do you drive through the subject intersection?

- Did you notice the marking?

- $\quad$ Do you know what the marking is for?
- How did you come to know about the marking?

Results from the media follow up survey included 100 subject of the school on campus community. $82 \%$ of the subjects were found to be using the intersection either regularly or on daily bases, shown in Table $\mathbf{2}$.

The survey shows that almost $70 \%$ of the subjects were aware of the marking function through media campaign but only $32 \%$ of the subjects driving through the intersection noticed the marking. Only $23 \%$ percent of the total survey population had the three yeses (drive through the 
intersection, saw the marking and know its use). We considered the percentage of people with three yeses at the survey is the percentage of people that the media campaign succeeded in conveying the message to and can benefit from the new marking. Still $23 \%$ was considered a fair penetration percentage. This is because some drivers knew the marking existed form the media campaign but did not see the marking or did not pay attention to it.

Table 2. Awareness Survey Results

\begin{tabular}{|c|c|c|}
\hline & Percentage (Yes) & Percentage (No) \\
\hline \hline Drive through the intersection & $82 \%$ & $18 \%$ \\
\hline Notice the marking & $32 \%$ & $68 \%$ \\
\hline Know the marking purpose & $70 \%$ & $30 \%$ \\
\hline Three yeses & $23 \%$ & $77 \%$ \\
\hline
\end{tabular}

The "after media" period followed the media campaign and the survey started in February and extended over March, April, May and June. Due to monitoring camera difficulties and adverse weather condition March data could not be recovered from one of the cameras. Thus March data was excluded from the analysis. This makes the "after media" period consist of February, April, May and June.

\section{Before-After Analysis of Marking Effectiveness}

As mentioned before, to analyze the "before", "after" and "after media" periods, data each 15 min were considered a separate data point then multiplied by 4 to get equivalent hourly rate. The number of RLR vehicles is divided by the corresponding volume and multiplied by thousand to get RLR rate per hour per one thousand vehicles.

The average number of red light runners in the test intersection for the "before" period was $66.59 \mathrm{rlr} / \mathrm{hr} / 1000$ veh and was $13.82 \mathrm{rlr} / \mathrm{hr} / 1000$ veh for the control intersection during the same time frame. For the "after" period (after marking installation) the RLR decreased in the test intersection to $49.57 \mathrm{rlr} / \mathrm{hr} / 1000$ veh recording $25.56 \%$ decrease. During the same period RLR increased at the control intersection to $17.70 \mathrm{rlr} / \mathrm{hr} / 1000$ veh recording an increase of $28.08 \%$ in the RLR at this location. For the "after media" time period the RLR rate decreased at the test intersection to $36.12 \mathrm{rlr} / \mathrm{hr} / 1000$ veh with $45.76 \%$ improvement, and the control intersection RLR decreased to $12.07 \mathrm{rlr} / \mathrm{hr} / 1000$ veh with only $12.66 \%$ improvement. Comparison of the average rates is shown in Table 3.

Considering the probabilistic definition of dilemma zone developed by Zegeer in 1977 [10], as he defined the dilemma zone by the zone upstream the stop bar where more than $10 \%$ and less than $90 \%$ of the drivers make the stop decision. From Fig. (8) we see that the marking also reduced the size of the dilemma zone by at least $50 \mathrm{ft}$, meaning that in addition to reducing the red light running rate the marking helped drivers make better stop/go decision. Drivers who were close to the stop bar made the go decision easier and more decisively, which can contribute to reducing the probability of rear end crashes caused by over defensive drivers making unnecessary sudden stops at the intersection when they could have passed safely.

As can be observed from Fig. (9) the average difference in RLR rate for the "before" period was $53 \mathrm{rlr} / \mathrm{hr} / 1000 \mathrm{veh}$, for the "after" period the difference was $32 \mathrm{rlr} / \mathrm{hr} / 1000$ veh (decrease of $39.62 \%$ from the "before" period), and for the "after media" period the difference between the two intersection decreased to $24 \mathrm{rlr} / \mathrm{hr} / 1000 \mathrm{veh}$ (decrease of $54.72 \%$ from the "before" period and decrease of $25.00 \%$ from the "after" period).

Conducting t-test for two sample assuming unequal variances of samples as in Table 4 parts (a), (b) and (c) we can conclude that the improvement after the marking installation (between "before" and "after" periods) is significant with P-value $=2.10 \times 10^{-19}$. The overall reduction in RLR rate due to the marking (between "before" and "after media" periods) is significant with $\mathrm{P}$-value $=3.50 \times 10^{-38}$. The effect of the media campaign alone can be concluded significant as well with $\mathrm{P}$-value $=4.77 \times 10^{-11}$.

\section{CONCLUSION}

It can be claimed with confidence that the marking had shown effectiveness as a RLR counter measure. The marking reduced the rates of RLR at the test intersection and a shift in the RLR rates trends. At the same time the control intersection supported the hypothesis that there has not been any major change in the RLR behavior between the different experiment periods. Thus the decrease in the RLR rate at the intersection can be claimed an effect of the marking and how much potential it has to help the driver take the proper stop/go decision and thus reducing RLR.

The marking showed good potential in reducing RLR, during the peaks of the RLR rates (in this case late night). This type of RLR can be considered dangerous because drivers are usually less alert during low traffic volume conditions and can easily get involved in an injury or fatal crash with a driver in the conflicting traffic.

The conclusions of this study are only preliminary and prove that the intersection has good potential as RLR countermeasure. However the marking should be tested on a larger number of intersections to examine how it performs under different traffic volumes and geometric features. The limitations of this study should be considered and a careful

Table 3. Total Average RLR Rate for Different Study Periods

\begin{tabular}{|c|c|c|c|c|}
\hline Study Period & $\begin{array}{l}\text { Test Intersection } \\
\text { (rlr/hr/1000 veh) }\end{array}$ & $\begin{array}{l}\text { Percentage } \\
\text { Change }\end{array}$ & $\begin{array}{l}\text { Control Intersection } \\
\text { (rIr/hr/1000 veh) }\end{array}$ & $\begin{array}{c}\text { Percentage } \\
\text { Change }\end{array}$ \\
\hline Before & 66.59 & -- & 13.82 & -- \\
\hline After & 49.57 & $-25.56 \%$ & 17.70 & $(+28.08) \%$ \\
\hline After media & 36.12 & $-45.76 \%$ & 12.07 & $-12.66 \%$ \\
\hline
\end{tabular}




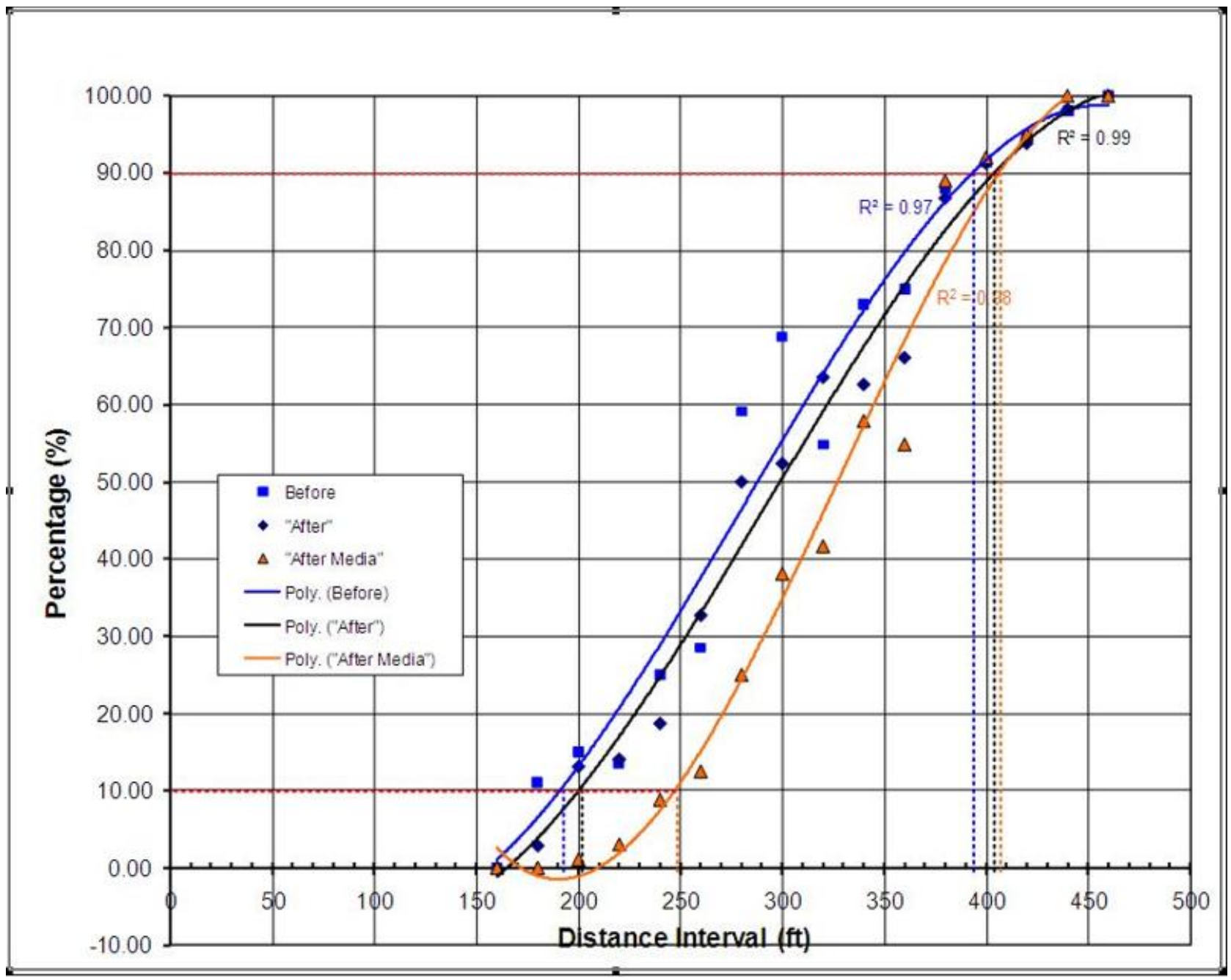

Fig. (8). Distribution of stopped drivers' percentage over the distance from the stop bar.

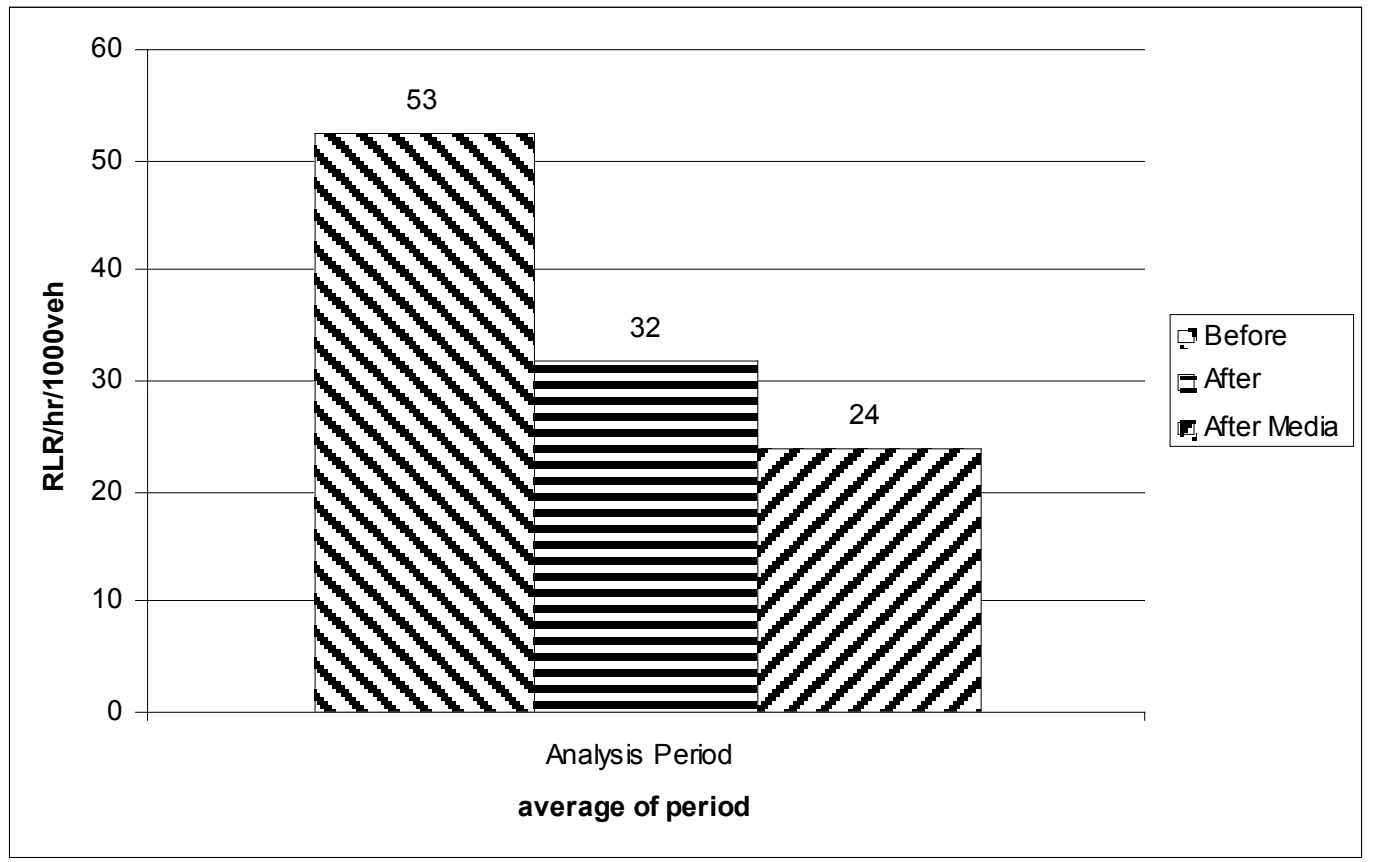

Fig. (9). Average RLR rate difference for each time period. 
Table 4. T-Test Two-Sample Assuming Unequal Variance

\begin{tabular}{|c|c|c|}
\hline \multicolumn{3}{|c|}{ (a) "Before" and "After" Periods } \\
\hline & Variable 1 & Variable 2 \\
\hline Mean & 52.77 & 31.87 \\
\hline Variance & 121650.75 & 31232.85 \\
\hline Observations & 27354 & 33555 \\
\hline Hypothesized Mean Difference & 0 & \\
\hline df & 38622 & \\
\hline t Stat & 9.01249428 & \\
\hline $\mathrm{P}(\mathrm{T}<=\mathrm{t})$ one-tail & $1.05 \mathrm{E}-19$ & \\
\hline t Critical one-tail & 1.644893082 & \\
\hline $\mathrm{P}(\mathrm{T}<=\mathrm{t})$ two-tail & $2.10 \mathrm{E}-19$ & \\
\hline t Critical two-tail & 1.960025353 & \\
\hline \multicolumn{3}{|c|}{ (b) "Before" and "After Media" Periods } \\
\hline & Variable 1 & Variable 2 \\
\hline Mean & 52.77 & 24.04 \\
\hline Variance & 121650.75 & 7060.72 \\
\hline Observations & 27354 & 14559 \\
\hline Hypothesized Mean Difference & 0 & \\
\hline df & 32909 & \\
\hline t Stat & 12.94 & \\
\hline $\mathrm{P}(\mathrm{T}<=\mathrm{t})$ one-tail & $1.75 \mathrm{E}-38$ & \\
\hline t Critical one-tail & 1.644899931 & \\
\hline $\mathrm{P}(\mathrm{T}<=\mathrm{t})$ two-tail & $3.50 \mathrm{E}-38$ & \\
\hline t Critical two-tail & 1.960036017 & \\
\hline \multicolumn{3}{|c|}{ (c) "After" and 'After Media" Periods } \\
\hline & Variable 1 & Variable 2 \\
\hline Mean & 31.87 & 24.04 \\
\hline Variance & 31232.86 & 7060.72 \\
\hline Observations & 33555 & 14559 \\
\hline Hypothesized Mean Difference & 0 & \\
\hline df & 47751 & \\
\hline t Stat & 6.58 & \\
\hline $\mathrm{P}(\mathrm{T}<=\mathrm{t})$ one-tail & $2.39 \mathrm{E}-11$ & \\
\hline t Critical one-tail & 1.644899931 & \\
\hline $\mathrm{P}(\mathrm{T}<=\mathrm{t})$ two-tail & $4.77 \mathrm{E}-11$ & \\
\hline t Critical two-tail & 1.96001361 & \\
\hline
\end{tabular}

examination of the marking should be done before attempting to further implement it.

\section{ACKNOWLEDGEMENTS}

The authors would like to acknowledge the Florida Department of Transportation (FDOT) for its sponsorship of this research project. The recommendations of this study are those of the authors and they do not represent views of FDOT.

\section{REFERENCES}

[1] J.L. Pline, Ed. Traffic Engineering Handbook, 5th ed. Institute of Transportation Engineers, Washington, D.C., 1999.

[2] K. Zimmerman, and J. A Bonneson, "Number of vehicles in the dilemma zone as a potential measure of intersection safety at highspeed signalized intersections", TRB 83rd Annual Meeting, Jan 11-15, 2004, Washington, D.C.

[3] T. Smith, "Effects of advanced warning flashers at signalized intersections on simulated driving performance", Advanced Transportation Technologies Seminar Series, Fall 2001. Available from: http://www.its.umn.edu/seminars/2001/fall/04smith.html, [access date, Jul 2004.]

[4] T. Sayed, H. Vahidi, and F. Rodriguez, "Advanced warning flashers: do they improve safety?" Transportation Research Record 1692, Washington, DC: Transportation Research Board, 1999.

[5] C. Quiroga, E. Kraus, I.V Schalkwyk, and J. Bonneson, "RED LIGHT RUNNING - A POLICY REVIEW”, CTS-02/150206-1, March 2003.

[6] Traffic Detector handbook, $3^{\text {rd }}$ ed., Federal Highway Administration, Publication number FHWA-HRT-06-108, October 2006. vol 12006.

[7] C. Newton, N. Mussa, R. Sadalla, K. E. Burns, and J. Matthias, "Evaluation of an alternative traffic light change anticipation system, Accident Analysis \& Prevention", vol. 29, no. 2, PP 201209, 1997.

[8] Institute of Transportation Engineers (ITE), Traffic Engineering Handbook, Washington, DC: Institute of Transportation Engineers, 1999.

[9] X. Yan, E. Radwan, and E. Birriel, "Analysis of red light running crashes based on quasi-induced exposure concept and multiple logistic regression method", Journal of the Transportation Research Board 2005.

[10] Xuedong Yan, Essam Radwan, and Dahai Guo, "Effect of the pavement-marking Countermeasure to Improve Signalizedintersection Safety", ITE Journal, Vol. 77 issue 8, pp. 30-39, 2007.

[11] C. Zegeer, "Effectiveness of green-extension systems at high-speed intersections", Kentucky Department of Transportation, Research Report 472, 1977.

[12] Manual of Uniform Traffic Control Devices (MUTCD), Federal Highway Administration, Washington, DC, 2003.

This is an open access article licensed under the terms of the Creative Commons Attribution Non-Commercial License (http://creativecommons.org/licenses/by-nc/ 3.0/) which permits unrestricted, non-commercial use, distribution and reproduction in any medium, provided the work is properly cited. 